\title{
NMR Studies of Chemical Exchange Processes in Intramolecularly Hydrogen Bonded o-Hydroxy-carbonyl Compounds
}

\author{
ULRICH KOELLE* and STURE FORSÉN
}

\author{
Department of Physical Chemistry 2, Chemical Center, P.0.B. 740, S-220 07 Lund, Sweden
}

Activation parameters for the restricted internal rotation in phenols with carbonyl residues in the 2- and 6-positions and in resorcinols with a carbonyl function in the 2-position were determined using complete lineshape analysis or coalescence measurements. Variations of the observed barriers with solvent and concentration and the large negative entropies of activation are discussed. A complex mechanism is suggested for the interconversion of the conformers to account for the experimental findings. IR frequencies for the OH-stretching vibration are recorded and compared with values for intermolecular complexes.

In contrast to the vast number of investigations dealing with the strength of intermolecular hy. drogen bonds, quantitative data on intramolec. ular bonds are more sparse. In the case of inter. molecular hydrogen bonds it is most straightforward to determine either equilibrium constants, from which the enthalpy changes on complex formation may be calculated, or to record these changes directly by forming the adducts. The $\Delta H^{\circ}$-values determined in this way are then frequently correlated with IR and PMR data for the chelated proton. ${ }^{1-4}$ For intramolecularly chelated hydrogens similar relations are not readily established due to the presence of one overwhelmingly predominant form in the equilibrium. In fact, only in the case of rather weak hydrogen bonds between a phenolic $\mathrm{OH}$. group and an adjacent halogen, was it possible to indirectly determine a value for the strength of this bond..$^{\mathrm{s}-\mathrm{s}}$

In phenols with donor substituents ortho to the OH-group, the intramolecular hydrogen

* Present address: Anorg. Chem. Inst. der RWTH, D.51 Aachen.

Acta Chem. Scand. A 28 (1974) No. 5 bond should stabilize the planar or nearly planar ground state 9,10 compared to the nonplanar transition state of internal rotation. Rotation of the donor - i.e. carbonyl residues - interchanges the chemical environments of $\mathrm{H}^{1}$ and $\mathrm{H}^{2}$ (see formulae) and that of the two protons in the meta positions with respect to the $\mathrm{OH}$-group,

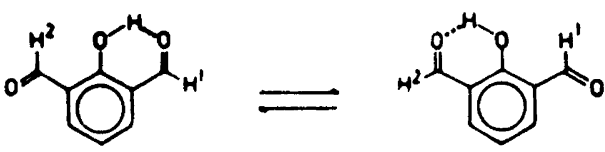

thus allowing the barrier to internal rotation to be studied by ${ }^{1} \mathrm{H}$ NMR lineshape analysis. It was anticipated that the height of this rotational barrier as measured by $\Delta G \neq$ or $\Delta H \neq$ should at least partly reflect the strength of the internal hydrogen bond. Values for 1 and 2 were recently published by Tabei, Tezuka and Hiroita. ${ }^{11}$ Our own results, which for 1 are based on the complete lineshape equations, instead of approximate formulas, are included in the publication.

\section{EXPERIMENTAL}

Melting and boiling points are not corrected. Melting points were determined on a Kofler microscope. IR spectra were recorded on a Perkin Elmer model 257 double beam grating spectrophotometer, using $0.1 \mathrm{~mm}$ or $1.0 \mathrm{~mm}$ $\mathrm{NaCl}$ cells. Mass spectra were run on an LKB 9000 A mass spectrometer with attached gas chromatography (GC) unit. ${ }^{2} \mathrm{H}$ NMR shift differences in $\mathrm{Hz}$ refer to spectra at $100 \mathrm{MHz}$.

a. Synthesis of materials

2,6-Diformyl-4-chlorophenol (1) was prepared by a procedure analogous to that described by 


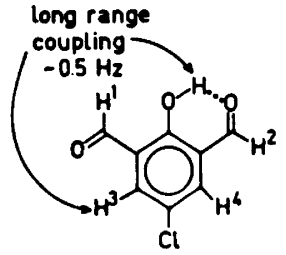

1<smiles>CC(=O)c1cc(C)cc2c1O[C]O2</smiles>

3

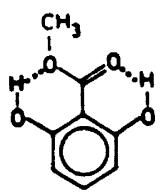

5<smiles>O=Cc1ccccc1</smiles>

7

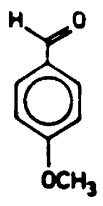

8<smiles></smiles>

2<smiles>COC(=O)c1cc(C)cc2c1O[C@H]2OC</smiles>

6<smiles></smiles>

6

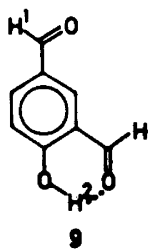

Ullman and Brittner ${ }^{12}$ for the 4-methyl compound (2) from 4-chlorophenol and formaldehyde, followed by oxidation of the 2,6-bishydroxymethylene intermediate to the bisformylphenol. Pale yellowish crystals, m.p. $122^{\circ} \mathrm{C}$ (ethanol). (Found: $\mathrm{C} \mathrm{51.9;} \mathrm{H} \mathrm{2.8;} \mathrm{Cl} \mathrm{19.2.} \mathrm{Requ.}$ C 52.0, H 2.7; Cl 19.2). ${ }^{1} \mathrm{H}$ NMR spectrum in $\mathrm{CD}_{2} \mathrm{Cl}_{2}\left(38^{\circ} \mathrm{C}\right)$ : singlet at $\tau=2.06\left(\mathrm{H}^{3}, \mathrm{H}^{4}\right)$, singlet at $\tau=-0.19(\mathrm{CHO})$, singlet at $\tau=-1.58(\mathrm{OH})$. The absorption at $\tau=2.06$ splits into an $\mathrm{AB}$ quartet below $-60^{\circ} \mathrm{C}\left(\Delta v_{\mathrm{AB}}=15.4 \mathrm{~Hz}, J_{\mathrm{AB}}=2.6\right.$ $\mathrm{Hz}$ ), and the aldehydic protons emerge as two lines at $\tau=0.0$ and -0.47 below the coalescence temperature.

2,6-Diacetyl-4-methyl phenol (3). $14.7 \mathrm{~g}(0.07$ $\mathrm{mol}$ ) of 2-methoxy-4-methyl isophthalic acid ${ }^{12}$ was heated with excess thionyl chloride until the acid was completely dissolved. Excess thionyl chloride was stripped and the residue dissolved in benzene. To this solution was added a benzene solution of $\mathrm{Cd}\left(\mathrm{CH}_{3}\right)_{2}$ (from $0.34 \mathrm{~mol}$ of $\mathrm{CH}_{3} \mathrm{MgI}$ and $31 \mathrm{~g}$ of anhydrous $\mathrm{CdCl}_{2}$ ) and

the mixture refluxed for $2 \mathrm{~h}$. It was then acidified with dil. $\mathrm{HCl}$, washed with water and aqu. $\mathrm{K}_{2} \mathrm{CO}_{3}$, dried and the solvent evaporated. The residual oil on distillation gave a fraction of 3 $\mathrm{ml}$ with b.p. $100-160^{\circ} \mathrm{C} / 0.1 \mathrm{mmHg}$ which showed strong carbonylic absorption near 1680 $\mathrm{cm}^{-1}$ in its IR spectrum. GC/mass spectral analysis $\left(3 \%\right.$ Silicon gum, $\left.160^{\circ} \mathrm{C}\right)$ of this oil revealed among other products with higher molecular weight a GC-peak $\left(R_{t}=3.5 \mathrm{~min}\right)$ with $m / e=206$, indicating 2,6-diacetyl-4-methylanisole. The oil was then warmed with $5 \mathrm{ml} 20 \% \mathrm{HCl}$ to hydrolyze possible esters derived from the starting acid, alkalized and extracted with $\mathrm{CH}_{2} \mathrm{Cl}_{2}$. The dried $\mathrm{CH}_{2} \mathrm{Cl}_{2}$-solution was treated with excess $\mathrm{BCl}_{3}\left(\mathrm{CH}_{3}\right)_{2} \mathrm{O}$ at room temp., the solvent and excess $\mathrm{BCl}_{3}$ removed in vacuo and the residue extracted with $10 \% \mathrm{NaOH}$ at $0^{\circ} \mathrm{C}$. The resulting phenolate solution was washed with ether, acidified and extracted with ether. After drying, evaporation of the solvent left $170 \mathrm{mg}$ of a solid which was purified by thick layer chromatography on Silica gel (Merck $\mathrm{HF}_{\mathbf{2 5 4}}$ )/ $\mathrm{CHCl}_{3}$ yielding $117 \mathrm{mg}$ pure 3 as yellowish crystals, melting at $70-72^{\circ} \mathrm{C}$ after sublimation in vacuo. (Found: C 68.7; H 6.3. Requ. C 69.2; $H$ 6.4). IR $\left(\mathrm{CCl}_{4}\right): \nu_{\mathrm{CO}}$ at 1645 and $1685 \mathrm{~cm}^{-1}$. ${ }^{1} \mathrm{H}$ NMR $\left(\mathrm{CDCl}_{3}\right): \tau=7.56$ (4-methyl), $\tau=7.20$ (acetyl), $\tau=2.04$ (aromatic protons), $\tau=-\mathbf{3 . 3 4}$ (OH).

2,6-Dicarbomethoxy-4-methyl phenol (4) was prepared from the corresponding acid ${ }^{12}$ and diazomethane. The well-protected $\mathrm{OH}$-group does not react with excess diazomethane. The product was white crystals melting at $119^{\circ} \mathrm{C}$ after sublimation in vacuo. ${ }^{1} \mathrm{H}$ NMR $\left(\mathrm{CD}_{2} \mathrm{Cl}_{2}\right)$ : $\tau=7.63$ (4-methyl), $\tau=6.07\left(\mathrm{COOCH}_{3}\right), \tau=2.07$ (aromatic protons), $\tau=-1.84(\mathrm{OH})$.

Methyl $\gamma$-resorcylate (5). A solution of $\gamma$ resorcylic acid in methanol was saturated with $\mathrm{HCl}$ gas and warmed for $5 \mathrm{~h}$ on a water bath. The product, which is insoluble in saturated $\mathrm{NaHCO}_{3}$, was collected. After sublimation it had m.p. $68-70^{\circ} \mathrm{C}$.

\section{b. ${ }^{1} \mathrm{H}$ NMR linesh a pe \\ measurements}

${ }^{1} \mathrm{H}$ NMR spectra were recorded on Varian A 60, HA 100, and XL 100 instruments. Complete lineshape analysis was performed only on 100 $\mathrm{MHz}$ spectra. Temperatures are $35^{\circ} \mathrm{C}$ when not stated otherwise. Low temperature measurement was done with a capillary fixed in the center of the NMR tube and filled with a mix. ture of methanol and dimethyl ether. The chem. ical shift difference between the ether $\mathrm{CH}_{3}$ - and the methanol $\mathrm{OH}$-protons was calibrated against the temperature. Temperatures measured in this way are believed to be accurate to at least \pm 0.3 degrees. When the signals from the capillary interfered with those of the compound or the solvent, as was the case with 3 and 6 , respectively, the same capillary in a separate NMR 
tube was used to check the temperature before and after recording the spectrum. Observed temperature differences were within $1^{\circ} \mathrm{C}$. Simula. tion of experimental ${ }^{1} \mathrm{H}$ NMR line shapes was carried out with computer programs based on McConnell's equations for the interchange of two uncoupled nuclei and on the treatment of Alexander for the strongly coupled cases. ${ }^{13}$

\section{RESULTS}

In order to perform a meaningful lineshape analysis, i.e. to evaluate the mean life time $\tau$ for a conformer at different temperatures by matching theoretical curves to experimental ones in such "simple" cases as coupled or uncoupled AB-systems, the shift difference $\Delta v$ and the natural line width $1 / \pi T_{2}$ at any temperature must in principle be known to remove ambiguities. These requirements are never fully met in the present cases. They are best fulfilled by compounds 1 and 5 where it is possible to extend the measurements far enough below the coalescence point to allow an extrapolation of $\Delta v .2$ does not give sharp signals for the aromatic protons and provides little information in addition to that extracted from the spectra of 1 . The difference in activation energy between 1 and 2 is believed to be smaller than the present experimental errors (see also Ref. 11). In 3 and 4 the shift difference between the coalescing meth. yl signals is too small for a complete separation at low temperature. The resorcinol derivative 2,6-dihydroxyacetophenone (6) is not soluble in the relatively inert solvents that can be used for the other compounds. Therefore the activation parameters in these solvents can only be presented for 1 and 5 . In the other cases values for $\Delta G \neq$ are given, which were evaluated by fitting calculated to experimental curves near the coalescent point.

To ensure that the signal averaging process can be neither due to nor concerted with an intermolecular proton exchange, the latter was shown to be slow compared with the intramolecular rotation of aldehyde and ester groups in compounds of the type in question. A mixture of the ester 5 with its $p$-methoxy derivative shows separate $\mathrm{OH}$ signals up to $90^{\circ}$. This has also been demonstrated for a mixture of the aldehydes 1 and 2 whose $\mathrm{OH}$ protons do not rapidly exchange at elevated temperatures.
For compound 1 both the signals from the aromatic protons and those from the aldehyde protons ( $\mathrm{H}^{\mathbf{1}}$ and $\mathrm{H}^{2}$ ) could be matched with calculated curves, giving essentially the same values for the mean life time $\tau$. Shift differences of both the aromatic and the aldehyde protons increase with temperature and were extrapolated from low temperature measurements. Apparent differences in line width between the aromatic protons at low temperature are attributed to ring proton-side chain long-range couplings such as those observed in similar systems ${ }^{14}$ (see formula). The signal due to $\mathrm{H}^{3}$ (at lower field) is about $0.5 \mathrm{~Hz}$ broader than that of $\mathrm{H}^{4}$ due to a small coupling with the $\mathrm{OH}$ proton. The AB quartet from the aromatic protons was thus treated as an $A B X$ case with nuclei $A$ and $B$ interchanging and with a natural line width $1 / \pi T_{2}$ of $1.8 \mathrm{~Hz}$ together with coupling constants $J_{\mathrm{AX}}=0.5 J_{\mathrm{BX}}=0$ and $J_{\mathrm{AB}}=2.6$ Hz. At higher temperatures gradually larger $T_{2}$-values have been used to account for the smaller natural linewidth. Measurements were performed on $0.1 \mathrm{M}$ solutions in 1:1 mixtures of $\mathrm{CD}_{2} \mathrm{Cl}_{2} / \mathrm{CDCl}_{3}$ as a compromise between solubility and low freezing point.

The internal rotation of 5 can only be studied from temperature-dependent linewidths of the OH proton signal(s), the spectral changes in the aromatic region being too small. As a consequence of the very large shift difference between the strongly and the more weakly bonded $\mathrm{OH}$ proton at low temperature $\left(255 \mathrm{~Hz}\right.$ at $-100^{\circ} \mathrm{C}$; see also Table 1), essentially no ${ }^{1} \mathrm{H}$ NMR absorption intensity is observed between $-65^{\circ} \mathrm{C}$ and $-25^{\circ} \mathrm{C}$. The Arrhenius plot thus has a low- and a high-temperature part, covering an overall range of about $120^{\circ} \mathrm{C}$. Also in this case the temperature dependence of the chemical shifts were extrapolated from low temperature data.

The aromatic protons of 3 and 4 are rather strongly coupled to the adjacent methyl group and are thus not suited for a complete lineshape analysis. The shift difference between the lines from the acetyl and carboxymethyl protons in 3 and 4, respectively, was too small for a complete separation, as mentioned above. The lines from these protons are still broadened at the lowest temperatures that could be reached in the NMR probe (about $-130^{\circ} \mathrm{C}$ ). The $\Delta G \neq$ value at the coalescence temperature as given in Table 1 may therefore include a somewhat

Acta Chem. Scand. A 28 (1974) No. 5 


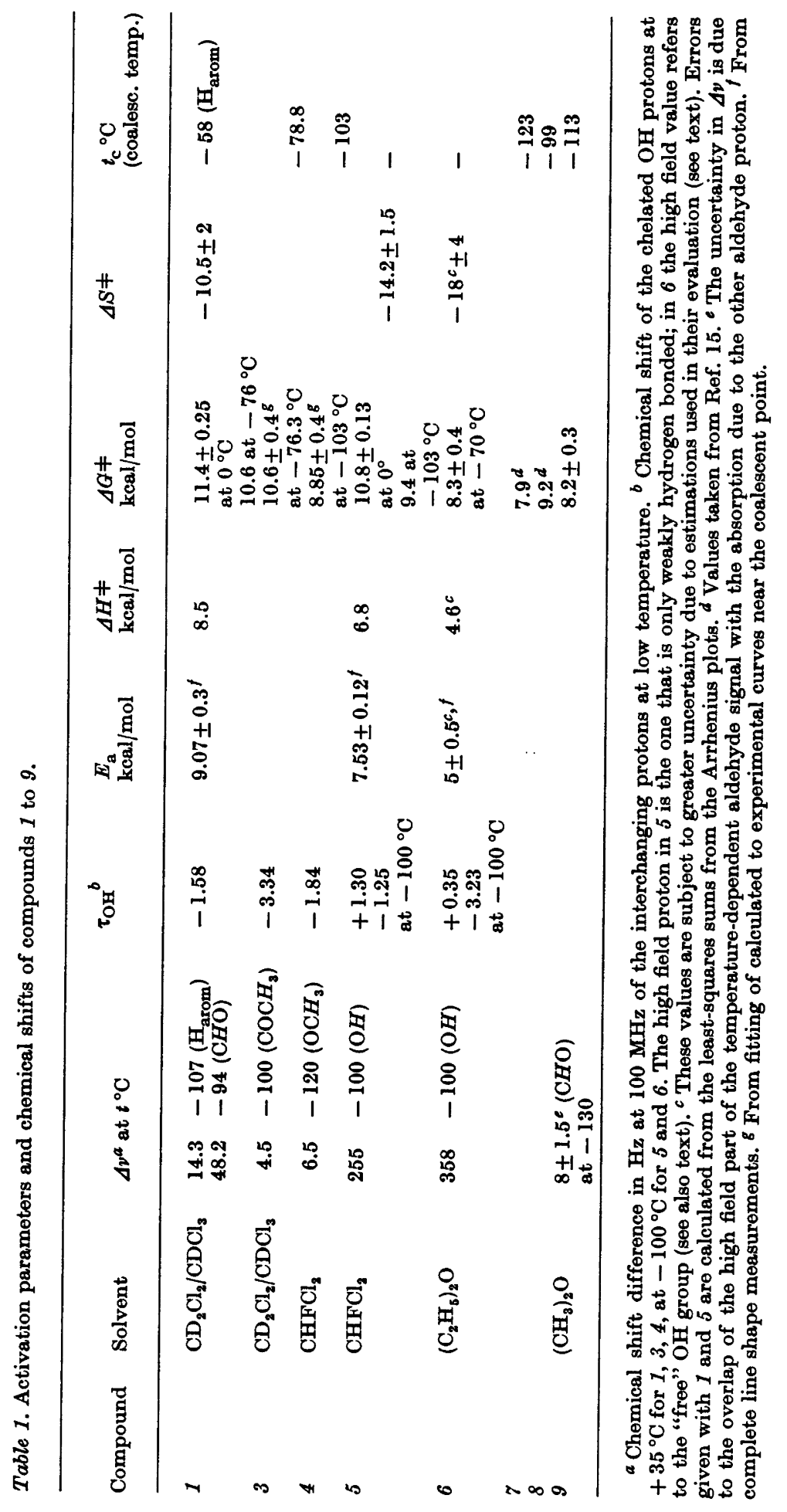

Acta Chem. Scand. A 28 (1974) No. 5 
greater uncertainty than for the other com. pounds.

2,6-Dihydroxyacetophenone (6) has one "free", or non-intramolecularly hydrogen-bonded $\mathrm{OH}$ group, which makes this compound insoluble in solvents even of the polarity of chloroform. In acetone, where it is readily dissolved, coalescence does not occur down to the freezing point of the solvent. As a compromise between requirements of "inertness" and solubility, diethyl ether was used as a solvent. The temperature had to be checked separately with the capillary between measurements. Only signals above the coalescence temperature were used for the evaluation of the activation parameters, taking $\Delta v$ from a low temperature spectrum where the $\mathrm{OH}$ signals are separated but still exchange-broadened.

The activation parameters of 1 through 6 are collected in Table 1, which also contains the three aldehydes 7,8 , and 9 with no internal hydrogen bonds at the interesting moiety, to allow comparisons. The values for benzaldehyde (7) and $p$-methoxybenzaldehyde (8) are taken from a paper by Anet and Ahmad.15

4-Hydroxyisophthalaldehyde (9) has an electronic structure close to those of 1 and 2 , but one free aldehyde group. The activation enthalpy for the interconversion of the free aldehyde group in 9 should thus be relevant to the series of interest. Proton $\mathrm{H}^{1}$ of compound 9 (see formula) splits into a doublet below $-113^{\circ} \mathrm{C}$ in dimethyl ether as solvent. The high field signal due to $\mathrm{H}^{1}$ then overlaps with the signal from $\mathrm{H}^{2}$, which renders $\Delta v$ somewhat uncertain. Taking $\Delta v=8 \pm 1.5 \mathrm{~Hz}$ from a spectrum at $-130^{\circ} \mathrm{C}$, the $\Delta G \neq$ given in Table 1 can be calculated.

The nearly equal values of $\Delta G \neq$ for the chloroaldehyde 1 and the ketone 3 initiated an experiment in which the rate of interconversion of an aldehyde and that of the corresponding ketone at a fixed temperature could be directly compared. For exact comparison of $k$ values at the same temperature, the 4-methyl aldehyde 2 was chosen instead of its chloro analogue 1 . The temperature-dependent lines of a 1:1 mixture of 2 and 3 in $\mathrm{CDCl}_{3} / \mathrm{CD}_{2} \mathrm{Cl}_{2}$ were recorded at $-70^{\circ} \mathrm{C}$. Simulated spectra could be fit with a $k$ value of $3.3 \mathrm{~s}^{-1}$ for 2 and one of $10 \mathrm{~s}^{-1}$ for 3 at this temperature, indicating a slower rotation of the aldehyde.

Influence of solvent and concentration

A marked influence of the solvent on the rotational barriers was not unexpectedly noted in many experiments. A solvent which can act as a hydrogen acceptor generally lowers the barrier. Table 2 is a compilation of activation parameters for 5 and 6 in different solvents. Diethyl ether is the only solvent in which the activation parameters of the compounds are directly comparable. 6 is not soluble in chloroform-like solvents (see above). For the ester 5 the rate of interconversion is enhanced on going from $\mathrm{CHFCl}_{2}$ to diethyl ether so that the splitting of the $\mathrm{OH}$ signal at low temperature was no longer observable. Assuming a value for $\Delta v$ similar to that in $\mathrm{CHFCl}_{2}$, the mean life $\tau$ was calculated from the width of the broadened line due to both $\mathrm{OH}$ protons at $-90^{\circ} \mathrm{C}$. Note that coalescence of 5 in $\mathrm{CHFCl}_{2}$ occurs around -50 ${ }^{\circ} \mathrm{C}$. Thus the difference in $\Delta G \neq$ for the two solvents in the case of compound 5 is about 3 $\mathrm{kcal} / \mathrm{mol}$. Coalescence of the $\mathrm{OH}$ protons of 6 in ether is observed around $-70^{\circ} \mathrm{C}$. In the more strongly proton accepting solvent acetone, only a slight broadening of the $\mathrm{OH}$ signal was noted

Table 2. Variation of $\Delta G \neq$ with solvent.

\begin{tabular}{lllcc}
\hline Compound & Solvent & $\Delta G \neq(\mathrm{kcal} / \mathrm{mol})$ & Temp. $\left({ }^{\circ} \mathrm{C}\right)$ & $\begin{array}{c}\text { Mean life time } \tau \\
\text { of rotamer }(\mathrm{s})\end{array}$ \\
\hline 5 & $\mathrm{CHFCl}_{2}$ & 9.5 & -92.3 & $9 \times 10^{-2}$ \\
5 & $\mathrm{CHFCl}_{2}$ & 9.5 & +6.1 & $5.1 \times 10^{-5}$ \\
5 & $\left(\mathrm{C}_{2} \mathrm{H}_{5}\right)_{2} \mathrm{O}$ & 6.6 & -92.3 & $5.1 \times 10^{-5}$ \\
6 & $\left(\mathrm{C}_{2} \mathrm{H}_{5}\right)_{2} \mathrm{O}$ & 8.3 & -70.0 & \\
6 & $\left(\mathrm{CH}_{3}\right)_{2} \mathrm{CO}$ & no coalescence; broadened signals at $-100^{\circ} \mathrm{C}$ \\
\hline
\end{tabular}

Acta Chem. Scand. A 28 (1974) No. 5 
down to $-100^{\circ} \mathrm{C}$, when the solvent freezes. It would be difficult to substitute these more qualitative figures by quantitative data because of the low solubility and the very low temperatures that are needed to separate the different $\mathrm{OH}$ protons under conditions of slow rotation.

To further substantiate the significance of the strongly negative values for $\Delta S \neq$ in Table 1, a study of the dependence of line shape upon concentration at a fixed temperature was performed with two compounds. The aldehyde signal of 1 above coalescence temperature became broader on dilution (Table 3), indicating a slower rotation at lower concentrations. A similar result was obtained with 5 , where the OH signals below coalescence sharpened when the concentration was decreased. The $k$ values for the two experiments, as given in Table 3, are extracted from calculated plots of the linewidth $\Delta v_{1 / 2} v s . k$ for the pertinent compounds with all other parameters the same as those used in the evaluation of the activation parameters of Table 1.

\section{Infrared studies}

Table 4 collects the IR stretching frequencies of the OH groups of compounds 1 through 6 . Data for salicylaldehyde and 0 -hydroxyacetophenone are included from Ref. 5. For 1, 3, and 4 (the spectrum of 2 closely resembles that of 1), one absorption due to the intramolecularly
Table 3. Concentration dependence of the linewidth of 1 and 5 .

\begin{tabular}{lllll} 
Comp. Conc. $(\mathrm{mol} / 1)$ & $\begin{array}{l}\text { Temp. } \\
\left({ }^{\circ} \mathrm{C}\right)\end{array}$ & $\Delta \nu \mathrm{Hz}^{a}$ & $k\left(\mathrm{~s}^{-1}\right)$ \\
\hline & & & & \\
\hline & 1.02 & -2 & 5.7 & $10^{3}$ \\
& 0.51 & & 9.0 & $0.5 \times 10^{3}$ \\
5 & 0.274 & -100 & 11 & $0.3 \times 10^{2}$ \\
& 0.137 & & 9.3 & $0.19 \times 10^{2}$ \\
\hline
\end{tabular}

a Signal width at half height.

bonded proton is seen. 6 has a "free" $\mathrm{OH}$ absorption at $3590 \mathrm{~cm}^{-1}$ and one broad band around $3050 \mathrm{~cm}^{-1}$ which must be assigned to the hydrogen bond. The IR spectrum of 5 very nicely shows the difference between the strongly (towards the carbonyl oxygen) and weakly (towards the methoxy oxygen) bonded $\mathrm{OH}$ proton with absorptions at 3470 and $3200 \mathrm{~cm}^{-1}$, respectively. Concentrations were kept at 0.01 $\mathrm{M}$, or below. Compound 1 was studied in $\mathrm{CCl}_{4}$ in the concentration range 0.05 to $0.0025 \mathrm{M}$ and from the absence of any changes in the spectrum it was concluded that the observed bands near $3000 \mathrm{~cm}^{-1}$ are due to monomers rather than higher associates.

To see how the spectrum would be influenced by the addition of bases such as pyridine or triethylamine which are known to form strong

Table 4. Activation parameters, IR frequencies $\left(v_{\mathrm{OH}}\right)$ and chemical shifts $\left(\tau_{\mathrm{OH}}\right) \cdot{ }^{a}$

Compound Solvent $\Delta H \neq(\mathrm{kcal} / \mathrm{mol}) \Delta G \neq(\mathrm{kcal} / \mathrm{mol}) \quad v_{\mathrm{OH}}\left(\mathrm{cm}^{-1}\right)^{b} \quad$ Solvent $\tau_{\mathrm{OH}} \quad$ Solvent

\begin{tabular}{|c|c|c|c|c|c|c|c|}
\hline $\begin{array}{l}1 \\
3\end{array}$ & $\begin{array}{l}\mathrm{CD}_{2} \mathrm{Cl}_{2} \\
\mathrm{CD}_{2} \mathrm{Cl}_{2}\end{array}$ & 8.5 & $\begin{array}{l}10.6 \\
10.6\end{array}$ & $3080 \mathrm{~b}$ & $\mathrm{CCl}_{4}$ & $\begin{array}{l}-1.58 \\
-3.34\end{array}$ & $\begin{array}{l}\mathrm{CD}_{2} \mathrm{Cl}_{2} / \mathrm{CD}_{3} \mathrm{Cl} \\
\mathrm{CD}_{2} \mathrm{Cl} / \mathrm{CD}_{3} \mathrm{Cl}\end{array}$ \\
\hline$\frac{4}{5}$ & $\begin{array}{l}\mathrm{CFHCl}_{2} \\
\mathrm{CFHCl}_{2}\end{array}$ & 6.8 & $\begin{array}{l}8.8 \\
9.4\end{array}$ & $\begin{array}{l}3150 b \\
3470 \mathrm{~s} \\
3200 \mathrm{~b}\end{array}$ & $\begin{array}{l}\mathrm{CCl}_{4} \\
\mathrm{CCl}_{4}\end{array}$ & $\begin{array}{l}-1.84 \\
-1.12\end{array}$ & $\begin{array}{l}\mathrm{CHFCl}_{2} \\
\mathrm{CHFCl}_{2}\end{array}$ \\
\hline $\begin{array}{l}5 \\
6\end{array}$ & $\begin{array}{l}E t_{2} \mathrm{O} \\
E t_{2} \mathrm{O}\end{array}$ & & $\begin{array}{l}6.7 \\
8.3\end{array}$ & $\begin{array}{l}3590 \mathrm{~s} \\
\text { near } 3050 \mathrm{~b}\end{array}$ & $\mathrm{CDCl}_{3}$ & -3.24 & $\mathrm{Et}_{2} \mathrm{O}$ \\
\hline \multicolumn{4}{|c|}{$\begin{array}{l}\text { Salicylaldehyde } d \\
o-\text { Hydroxyacetophenone } d\end{array}$} & $\begin{array}{l}3140 \\
3040\end{array}$ & $\begin{array}{l}\mathrm{CCl}_{4}^{5} \\
\mathrm{CCl}_{4}^{5}\end{array}$ & -2.37 & \\
\hline
\end{tabular}

${ }^{a}$ For temperatures to which activation parameters and $\tau$ values refer, see Table $1 .{ }^{b} \mathrm{~s}$, sharp; $\mathrm{b}$, broad. ${ }^{c}$ Interfering with methyl-stretch near $3000{ }^{d}$ From Ref. 5. 
intermolecular complexes with phenols in hydrocarbons or $\mathrm{CCl}_{4}, 2$ spectra were also recorded in the presence of these bases. The samples were added to a solution of the base in $\mathrm{CCl}_{4}$ using the same solution as reference in the double beam spectrometer. Only the "free" OH group of 6 at $3590 \mathrm{~cm}^{-1}$ is broadened and shifted to lower frequencies on addition of base. In no other case was a significant change in the IR spectrum noted on addition of pyridine or triethylamine in great excess. This is especially noteworthy for 5, whose weak hydrogen bond towards the ether oxygen is obviously not broken by a strong base. On the other hand, the relative strength of hydrogen bonds in pyridine/phenol and carbon$\mathrm{yl} / \mathrm{phenol}$ complexes is illustrated by the fact that the absorption at $3250 \mathrm{~cm}^{-1}$ in a solution of $p$-hydroxybenzaldehyde in chloroform, which must be assigned to the stretching mode of the intermolecular $=\mathrm{O} \cdots \mathrm{H}-\mathrm{O}-$ complexed $\mathrm{OH}$. group is shifted towards $3000 \mathrm{~cm}^{-1}$ on addition of pyridine.

Fig. 1 is a plot of $\Delta v_{\mathrm{OH}} v s$. the chemical shifts of the proton. It is seen that with the exception of 1 the frequently observed correlation ${ }^{7,8}$ between IR frequencies and chemical shifts exists also in the present cases.

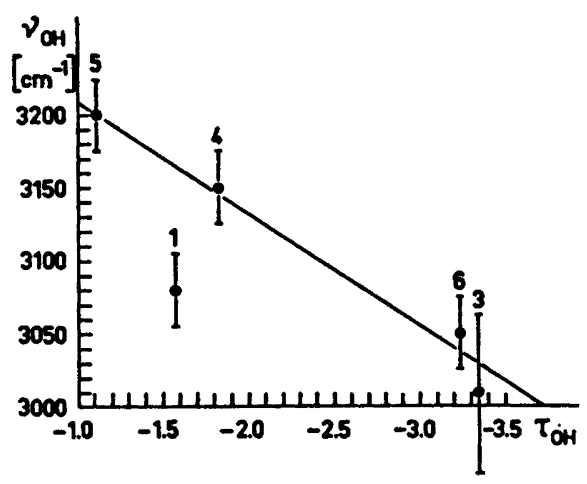

Fig. 1. Plot of the infrared shift $\Delta v_{\mathrm{OH}} v s$. the chemical shift $\tau_{\mathrm{OH}}$.

\section{DISCUSSION}

In the initial stages of this work, our main goal was an attempt towards the determination of the strength of intramolecular hydrogen bonds between a phenolic OH group and an adjacent carbonyl function. If the internal rota- tion of the latter is associated with the rupture and reforming of the intramolecular hydrogen bond, the enthalpy of this bond will make a significant contribution to the overall barrier. This should be corroborated by a variation of the barrier height with the basicity of the carbonyl group acting as the donor.

Comparison of the activation parameters from Table 1 makes it evident that $\Delta G \neq$ and $\Delta H \neq$ for compounds 1 through 6 are not very much greater than those observed in the structurally related aldehydes 7,8 , and 9 , which do not have a hydrogen bond. Apart from the hydrogen bond interaction energy, it would be expected that the presence of one or more OH groups ortho or para to the carbonyl group would cause a slight increase in the barrier to internal rotation, whereas a second carbonyl group in the meta position should exert a minor effect. The measured $\Delta G \neq$ values for 7 through 9 indicate the correctness of this assumption.

The strengths of intramolecular bonds in chelated phenols such as $o$-hydroxyacetophenone have never been directly determined. From the low chemical shift of the chelated proton and its broad infrared absorption at low frequencies, as well as the lack of unchelated, "open" conformer in the equilibrium, it was frequently concluded that these hydrogen bonds are rather strong, ${ }^{18-18}$ i.e. $>5 \mathrm{kcal} / \mathrm{mol}$. A figure of this order of magnitude must be considered a lower limit if the relations between $\Delta H^{\circ}$ and IR as well as ${ }^{1} \mathrm{H}$ NMR shifts for intermolecular complexes are applied to the intramolecular chelates (see below). If the interconversion process in 1 through 6 would require a complete breaking of the hydrogen bond, the enthalpy change for this process must be added to the enthalpy of activation for the rotation of a non-hydrogen bonded aromatic carbonyl compound. Thus the barriers would be expected to be at least of the order of 13 to $15 \mathrm{kcal} / \mathrm{mol}$. The experimental values in Table 1 are significantly lower. Two alternative conclusions may be drawn from these findings:

(i) The intramolecular hydrogen bond energies in chelated phenols have been greatly overestimated, or

(ii) the interconversion process in 1 through 6 occurs in such a way that the hydrogen bond energy is partly retained, for example through solvent interaction or formation of bimolecular 
complexes.*

Significant differences in the activation parameters of Table 1 in the series 1 through 6 are observed between aldehydes and ketones compared with the esters, the latter having barriers lower by roughly $2 \mathrm{kcal} / \mathrm{mol}$ (compare 1,3 and 5). The order is the same as that found by Porte, Gutowsky and Hunsberger ${ }^{16}$ in $a^{1} \mathrm{H}$ NMR study, where increasing chemical shifts indicated a stronger hydrogen bond in the order ester, aldehyde, ketone. Comparison of the $\Delta G \neq$ values in Table 1 and the hydroxylic chemical shifts in 1,3 , and 4 makes it clear that these two parameters are not exactly parallel because the greater downfield shift of 3 compared with 1 is not reflected in the barrier (see also below). The lower barrier of the ester 4 may be due to a weaker hydrogen bond or to a less pronounced double bond character of the $\mathrm{C}_{\text {aryl }}-\mathrm{C}=\mathrm{O}$ bond. The same trend is revealed again in compounds 5 and 6 in ether solution (Table 2), where the difference between $5\left(\Delta G \neq-93{ }^{\circ} \mathrm{C}=6.6 \mathrm{kcal} / \mathrm{mol}\right)$ and $6\left(\Delta G \neq-70^{\circ} \mathrm{C}=8.3 \mathrm{kcal} / \mathrm{mol}\right)$ can hardly be attributed to the temperature difference of 23 ${ }^{\circ} \mathrm{C}$. The difference between 4 and 5 as reflected by the $\Delta G \neq$ values at $-103^{\circ} \mathrm{C}$ is indicative of the weak second hydrogen bond present only in 5 .

The greater stabilization of the ketone relative to the aldehyde, which would be expected from ${ }^{1} \mathrm{H}$ NMR and IR data, ${ }^{14,16}$ is not observable from the activation energy data in Table 1.

Direct evidence for which group has the greater hydrogen bonding capacity is given by 2-acetyl-6-formylphenol, where the pattern of long-range couplings in a sample in $\mathrm{CDCl}_{3}$ solution at room temperature is only consistent with a conformer that has its hydrogen bond directed exclusively towards the acetyl group. ${ }^{10}$ On the

* Note added in proof. A recently performed calorimetric determination of the heats of neutralization for the tetrabutylammonium salts of salicylaldehyde and 4-hydroxybenzaldehyde in butanone as a sol. vent did give values $\Delta H_{\text {neutr }}=-19.8 \mathrm{kcal} / \mathrm{mol}$ for the 2-hydroxy- and $\Delta H_{\text {neutr }}=-19.0 \mathrm{kcal} / \mathrm{mol}$ for the 4-hydroxycompound. This minor difference in neutralization enthalpy is corroborating our suggestion that hydrogen bonding of intramolecularly chelated phenols to proton accepting solvents is of major importance.

We are indebted to Doc. G. Olofsson at the Thermochemical Inst., Kemicentr. in Lund for doing the measurements. other hand, the $k$-values for the mixture of 2 and 3 clearly show a faster rotation in the ketone. From the IR absorption studies of the $\mathrm{OH}$ and $\mathrm{C}=\mathrm{O}$ stretching frequencies of salicylaldehyde and $o$-hydroxyacetophenone, the difference in hydrogen bond energy between $a$ chelated aldehyde and a ketone would be expected to be of the order of $1 \mathrm{kcal} / \mathrm{mol}$, in favor of the ketone, if the equation of Drago and Epley $^{2}$ (see eqn. (1) p. 540) is applied to the values given in Ref. 14 (see Table 4). The fact that this difference is not reflected in the rotational barriers of 1,2 , and 3 may be rationalized by a bimolecular complex undergoing rotation (see below). Here the assistance of a second molecule parallels its hydrogen bonding capacity, which cancels the stronger stabilisation of the ground state.

The solvent dependence of the barriers demonstrated with compounds 5 and 6 is in accord with the findings of Frankle and Laszlo, ${ }^{20}$ who noted a marked decrease of the barrier to internal rotation in Vorländer adducts (di[4,4dimethylcyclohexanedione $(2,6)]$ methanes) when changing to solvents with a greater hydrogen bonding ability. The authors suggest that in the cases of basic solvents the interconverting species are those whose internal hydrogen bonds are broken by the solvent. The IR absorptions of such complexes should be different from those in the intramolecularly hydrogen bonded molecules, but this could not be confirmed with the present substances. Besides the IR shifts, the ${ }^{1} \mathrm{H}$ NMR shifts also seem to be rather insensitive towards added base. Pyridine for example, added in great excess to a dilute sample of salicylaldehyde, shifts the $\mathrm{OH}$ proton not more than a few $\mathrm{Hz}$ to lower field, an effect that may reflect solvent anisotropy changes rather than the formation of appreciable amounts of a species with a broken intramolec. ular hydrogen bond. Considering the very high rates established for the formation of hydrogen bonds, ${ }^{21}$ only a small fraction of intermolecularly hydrogen bonded molecules in the equilibrium is necessary to account for the enhanced rotational rates. The influence of concentration on the interconversion rate, which was demonstrated with compounds 1 and 5 , suggests a second-order process. Because of the relatively small range of concentrations accessible, it was not possible to establish quantitative depend-

Acta Chem. Scand. A 28 (1974) No. 5 
ence of the rotational rates upon the concentration and thus evaluating the kinetic order of the process in question. A purely second order process would require the interconversion rate to be proportional to the concentration. The observed effects are slightly smaller and therefore different pathways must also be taken into account, which may be operative to varying extents depending on the compound, the solvent and the concentration.

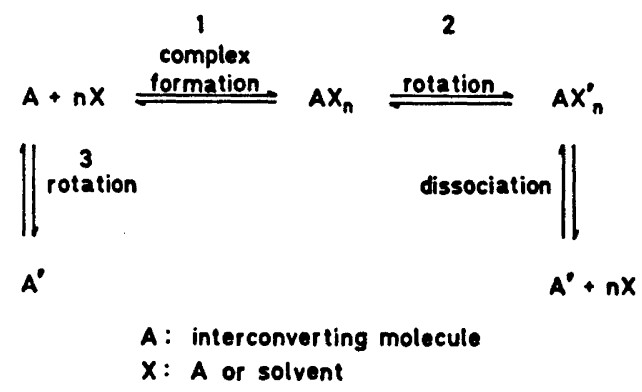

Fig. 2. Possible reaction pathways for the interconversion of 1 through 6 .

Fig. 2 depicts two such pathways, where $A$ is the interconverting molecule and $\mathrm{X}$ is either a second A molecule or a solvent molecule. The fraction of $\mathrm{AX}_{n}$ may be small in the equilibrium, but if process 1 is fast enough compared to 2 the latter will still be rate determining. It is further assumed that rotation of the uncomplexed molecules, i.e. process 3 , is much slower than 2. An overall rate which is composed of individual pathways differing in the association number $n$ and the nature of $\mathrm{X}$ may then account for the experimental results.

Although our experimental data seem to be insufficient to describe the exact nature of the interconverting species, two possible models for the complex $\mathbf{A X}_{n}$ are depicted in Fig. 3. Path I $\left(\mathrm{AX}_{n}=\mathrm{Ia}\right)$ implies that complex formation occurs prior to and kinetically independent of the rupture of the intramolecular bond, the latter weakening successively in favour of the intermolecular bond on reaching the transition state of rotation. In II the intramolecular bond is broken together with complex formation (IIb) followed by rotation of the carbonyl residue. Both pathways account for the solvent and concentration dependence of the barriers observed. An argument in favour of II is the large

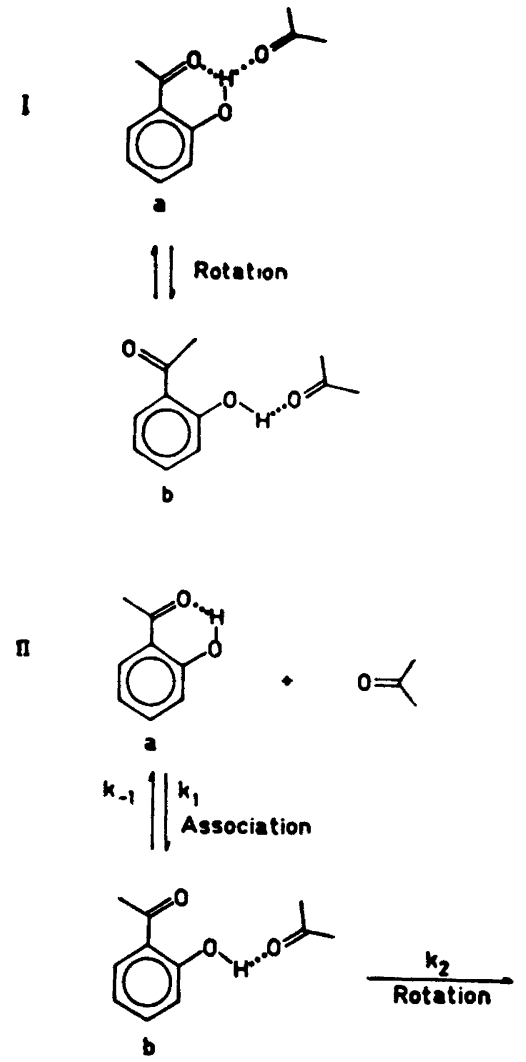

Fig. 3. Possible interconverting species of 1 through 6 .

negative entropy of activation. Complexes of type Ia should make a substancial equilibrium fraction and the degree of ordering of the solvated chelate should not be drastically changed during the interconversion. The net entropy effects should then be small. In contrast, the equilibrium fraction of complexes of type IIb should be small, and as long as $k_{-1} \gg k_{2}$, the activation entropy, $\Delta S \neq$, is largely determined by the association process.

Intermolecular complexes formed by bases like carbonyl compounds or amines with phenols have been the subject of numerous investigations, and $\Delta H^{\circ}$ values for the formation of these complexes have recently been determined by direct thermodynamic measurements of the heat of mixing by Drago and coworkers., ${ }^{2,4,22}$ Drago and Epley ${ }^{2}$ thus found $\Delta H^{\circ}$ values for the systems phenol-pyridine and phenol/triethylamine to be -7.2 and $-8.3 \mathrm{kcal} / \mathrm{mol}$ respec-

Acta Chem. Scand. A 28 (1974) No. 5 
tively, whereas carbonyl bases like acetone yield enthalpies of only $-5 \mathrm{kcal} / \mathrm{mol}^{3}$ The fact that no spectral changes occur on addition of pyridine or triethylamine to the phenols 1 through 6 (not even the "weak" hydrogen bond in 5 is altered) may be rationalized by the negative entropies of mixing observed in several cases. ${ }^{4,23}$ Part of the enthalpy expected to favour the intermolecular complex is consumed by the entropy change that parallels the breaking of the intramolecular or the formation of the intermolecular bond. This finding is further support for the path II discussed above, where the interconversion process observed in the NMR is connected with a substantial change in entropy.

Drago and Epley ${ }^{2}$ present the equation

$-\Delta H^{\circ}=\left(0.015 \Delta v_{\mathrm{OH}}+3\right) \mathrm{kcal} / \mathrm{mol}$

which relates the enthalpy change on formation of the hydrogen bond to the corresponding IR frequency shift. If applied to the intramolecularly hydrogen bonded phenols, a $\Delta H^{\circ}$ value of $8.7 \mathrm{kcal} / \mathrm{mol}$ follows for 6 if $\Delta v_{\mathrm{OH}}$ is equated to the frequency difference between the complexed and the uncomplexed $\mathrm{OH}$ group (see Table 4). Similar values are obtained for the other compounds in the series if the absorption of free phenol in dilute solution at $3600 \mathrm{~cm}^{-1}$ is taken as reference. Though it appears uncertain if the above equation also gives correct results for intramolecular chelates, it should allow at least an estimate of their strength. From the activation parameters it then appears quite obvious that the major fraction of the hydrogen bond enthalpy must be conserved during the internal rotation by either intermolecular association or through solvation by the polar solvents.

Acknowledgement. We are indebted to Mrs. Annika Raihle for experimental assistance with the syntheses, to Dr. Torbjörn Drakenberg for placing the lineshape computer programs at our disposal and to Dr. Robert E. Carter for unfailing interest and moral support as well as linguistic criticism. We wish to thank Mrs. Berit Rosberg for drawing the original figures. Part of the work was supported by an NFR grant to one of us (U.K.).

\section{REFERENCES}

1. For reviews see: a. Pimentel, C. and McClellan, A. L. The Hydrogen Bond, Freeman, San Francisco 1960; b. Pimentel, C. and
McClellan, A. L. Annu. Rev. Phys. Chem. 22 (1971); c. Vinogradov, A. N. and Linnell, R. $\mathrm{H}$. Hydrogen Bonding, Van Nostrand, New York 1971 .

2. Drago, R. S. and Epley, T. D. J. Amer. Chem. Soc. 91 (1969) 2883.

3. Epley, T. D. and Drago, R. S. J. Amer. Chem. Soc. 89 (1967) 5770.

4. Joesten, M. D. and Drago, R. S. J. Amer. Chem. Soc. 84 (1962) 3817; Drago, R. S., O'Bryan, N. and Vogel, G. C. J. Amer. Chem. Soc. 92 (1970) 3924.

5. Baker, A. W. J.Amer. Chem. Soc. 80 (1958) 3598.

6. Brown, I., Ellington, G. and Martin-Smith, M. Spectrochim. Acta 18 (1962) 1593.

7. Reeves, L. W., Allan, E. A. and Strømme, K. O. Can. J. Chem. 38 (1960) 1249.

8. Allan, E. A. and Reeves, L. W. J. Phys. Chem. 66 (1962) 613.

9. Jones, N. and Curl, R. F. J. Mol. Spectrosc. $42(1972) 65$.

10. Diehl, P. and Henrichs, P. M. J. Magn. Resonance 5 (1971) 134.

11. Tabei, M., Tezuka, T. and Hiroita, M. Tetrahedron Lett. (1971) 301.

12. Ullmann, F. and Brittner, K. Ber. Deut. Chem. Ges. 42 (1909) 2539.

13. See, e.g., Sutherland, I. O. Annu. Rep. $N M R$ Spectrosc. 4 (1971) 71 , and references therein.

14. Forsén, S., Ákermark, B. and Alm, T. Acta Chem. Scand. 18 (1964) 2313.

15. Anet, F. A. L. and Ahmad, M. J. Amer. Chem. Soc. 86 (1964) 119.

16. Porte, A. L., Gutowsky, H. S. and Hunsberger, I. M. J. Amer. Chem. Soc. 82 (1960) 5057.

17. Hay, R. W. and Williams, P. P. J. Chem. Soc. (1964) 2270.

18. Magnusson, L. B., Craig, C. A. and Postmus, C. Jr. J. Amer. Chem. Soc. 86 (1964) 3958.

19. Koelle, U. and Forsén, S. Unpublished results; cf. Forsén, S. and A kermark, B. Acta Chem. Scand. 17 (1963) 1712.

20. Frankle, W. E. Ph. D. Thesis, Princeton 1970.

21. See Ref. 1c, p. $264 \mathrm{ff}$.

22. Eyman, D. P. and Drago, R. S. J. Amer. Chem. Soc. 88 (1966) 1617 .

23. Nagakura, S. J. Amer. Chem. Soc. 76 (1954) 3070 .

Received January 7, 1974. 